Historic, archived document

Do not assume content reflects current scientific knowledge, policies, or practices. 



\section{Clitocybe Root Rot of Woody Plants in the Southeastern United States}

By Arthur S. Rhonds, formerly pathologist, Division of Forest Pathology, Bureau of Plant Industry, Soils, and Agricultural Engineering, Agricultural Research Administration, United States Department of Agriculture

\section{CONTENTS}

Introduction

History, host plants, and economic importance

Symptoms

Causal fungus

Isolations of the fungus

Inoculation experiments

Relative susceptibility and resistance of host plants in Florida.
Page

1 Relation of incidence of the disease to timbered lands and soil conditions

Control measures and treatment of diseased trees

Summary _...

Literature cited $\ldots \ldots$

\section{INTRODUCTION}

Clitocybe root rot, caused by the fungus Clitocybe tabescens (Fr.) Bres., is a destructive disease of fruit, forest, shade, and ornamental trees, shrubs, and vines, reported to occur from eastern Texas, Oklahoma, Missouri, southern Illinois and Indiana, West Virginia, Virginia, and the District of Columbia southeastward to Florida. Although the causal fungus occurs as far north as New York and Michigan, root rot caused by it has not been reported from the Northern States.

The root rot caused by $C$. tabescens is so similar in its general aspects to that caused by the closely related root rot fungus A rmillaria mellea Fr., that, in the absence of the fruiting bodies or of cultural studies, the diseases caused by these respective fungi may be confused readily. As a result, the diagnosis of such root rots, particularly in sections where both may occur, may be questionable in some cases. Apparently many cases of mushroom root rot, in the absence of

${ }^{1}$ Much of the work reported here was performed while the writer was employed as pathologist at the Florida Agricultural Experiment Station. 
fruiting bodies or cultural studies, particularly in the more northern States, have been attributed arbitrarily to $A$. mellea. Since $A$. mellea occurs in all States where $C$. tabescens may be found, this is an unsafe procedure. A. mellea also occurs more or less frequently in parts of northern Florida. Apparently, the higher temperature range in Florida is more favorable for optimum growth of $C$. tabescens.

\section{HISTORY, HOST PLANTS, AND ECONOMIC IMPORTANCE}

Clitocybe root rot was reported first from Oklahoma in 1901 by Wilcox (33), ${ }^{2}$ who stated that it had been destructive to apple, cherry, and peach trees there for a number of years. He estimated that in many cases whole peach and apple orchards had been destroyed by this disease in 2 years. In addition, he found the fungus to be a common parasite and saprophyte on four species of oaks.

Unfortunately, Wilcox considered the Oklahoma fungus as a distinct species from the one that had been so well described previously from Ohio by Morgan (14) as Agaricus (Clitocybe) monaldelphus, purely on the basis of slight differences in morphology and its parasitic habit of growth, and named it $C$. parasitica. This fungus has been described under various other names in the United States, although Bresadola pointed out in 1900 (3) and again in 1928 (4) that he considered the American plant synonymous with $C$. tabescens of Europe. It even has been confused with Armillaria mellea, having been erroneously regarded by some mycologists as an exannulate form of that fungus. The writer (19) has reviewed the synonymy of $C$. tabescens, and more recently (2.5) has presented the results of a comparative study of the cultural characteristics of these two closely related root rot fungi, clearly showing that they are distinct species. The fact that Wilcox (3.3) mentioned and illustrated the occurrence of black, shoestringlike rhizomorphs in connection with Clitocybe root rot indicates that both this and Armillaria root rot undoubtedly occurred in Oklahoma and that these similar root rots must have been confused by him in the absence of cultural studies. This is confirmed by a recently issued host index of Oklahoma plant diseases (18) in which both $\dot{C}$. tabescens and $A$. mellea are listed as occurring on various plants in that State. While Wilcox (33) in 1901 mentioned Clitocybe root rot as occurring on four species of oaks in addition to fruit trees in Oklahoma, Preston (18) in 1945 merely listed $C$.tabescens and its synonyms as occurring on hickory (Carya aiba), bur oak (Quercus macrocarpa), and blackjack oak (Q. maritandica), in addition to apple, cherry, peach, and grape.

Faurot $(\%)$ reported observing root rot caused by toadstool-bearing fungi to be of very common occurrence and a fatal disease of orchard trees in some scetions of southern Missouri in 1902. Duggar (5, p. 4\%1) stated that he had observed the Clitocybe root rot fungus to occur abundantly during favorable seasons at Columbia, Mo., on roots of hickory and other deciduous trees but failed to observe its occurrence in orchards, despite special effort to find it. The writer (19), who found this fungus to be the cause of a previously undetermined root rot of grapevines, as well as of orchard trees, in southern Missouri,

\footnotetext{
${ }^{2}$ Italic numerals in parentheses refer to Literature Cited, p. 24.
} 
observed it fruiting in great profusion from the roots of dead trees, stumps, and living trees in an area of forest, dominantly oak, a few miles from Neosho in the Ozark section. He also found it fruiting on the roots of a declining silver maple (Acer saccharinum) street tree at Neosho.

Walker (32) and Hewitt and Hayhurst (10, p. 424) reported that root rot of fruit trees was widespread in Arkansas and caused serious damage in some localities. Walker (32) stated that "besides the apple, it affects probably all the commonly cultivated fruit trees, the grape, as well as a number of forest trees," and that the disease is caused by toadstool fungi, two forms concerned being Clitocybe parasitica and A rmillaria mellea. A much later report $(1, p .48)$ from that State mentioned that both these fungi had been under observation for a number of years and had been found commonly parasitizing several types of plants, including privet hedges and apple and peach trees, as well as grapevines.

Stevens and Hall (29) reported the death of trees in apple orchards in Hayward County, N. C., and stated that "investigation showed the presence of a fungus, which, to all appearances, was Clitocybe parasitica." Fromme (9), in a report on the black root rot disease of apple, caused by Xylaria mali, stated that "the symptoms allow this disease to be easily distinguished from the so-called white root rot (believed to be caused by Clitocybe monadelpha) which occurs in some parts of Virginia occasionally, causing an appreciable loss of apple trees." It has been suggested by Dr. J. S. Cooley, of the United States Department of Agriculture, that Clitocybe possibly was blamed for some root rots of fruit trees that may have been due to Corticium galactinum before this fungus was adequately described. He considers this particularly true in the northern limits of Clitocybe, as in Virginia.

Authentic records of the occurrence of Clitocybe root rot in Florida have been found by the writer to date back to 1902, when it was recorded by Dr. H. Harold Hume, of the Florida Agricultural Experiment Station, on peach and other trees at Lake City, and records of the sudden dying of guava trees from what undoubtedly was this disease have been found dating back to 1885. It was reported by Hole (12) in 1905 , as troublesome in peach orchards on newly cleared hammock land at Fulton, east of Jacksonville, near the mouth of the St. Johns River. Fawcett $(8, p .66)$, in 1911, mentioned this as one of the peach diseases being studied by O. F. Burger. The destructiveness of this disease in a commercial peach planting on newly cleared pine-oak land near Blanton, Fla., was reported by the writer (21) and also by Thornton (30) in 1940. According to the estimate of the latter, root rot had attacked 38 percent of the 1,400 trees by the time they had attained an age of $31 / 2$ years and had killed 192 trees.

In the earlier records of Clitocybe root rot the disease attracted attention chiefly as an important cause of loss in orchard trees and, later, grapevines. Even in subsequent years, with the exception of Florida, only the most meager observations have been made in regard to its occurrence on forest, shade, and ornamental trees and shrubs. Extensive studies of this disease have been conducted by the writer in Florida over a period of 20 years. Some results were published in the Florida Agricultural Experiment Station Annual Reports and in 
various bulletins. These studies have shown that Clitocybe root rot is of frequent and widespread occurrence in that State, attacking forest and fruit trees, tung-oil trees, and a large variety of ornamental trees, shrubs, and vines (20), including many exotic ones. It has been recorded as attacking 210 species of plants belonging to 137 genera

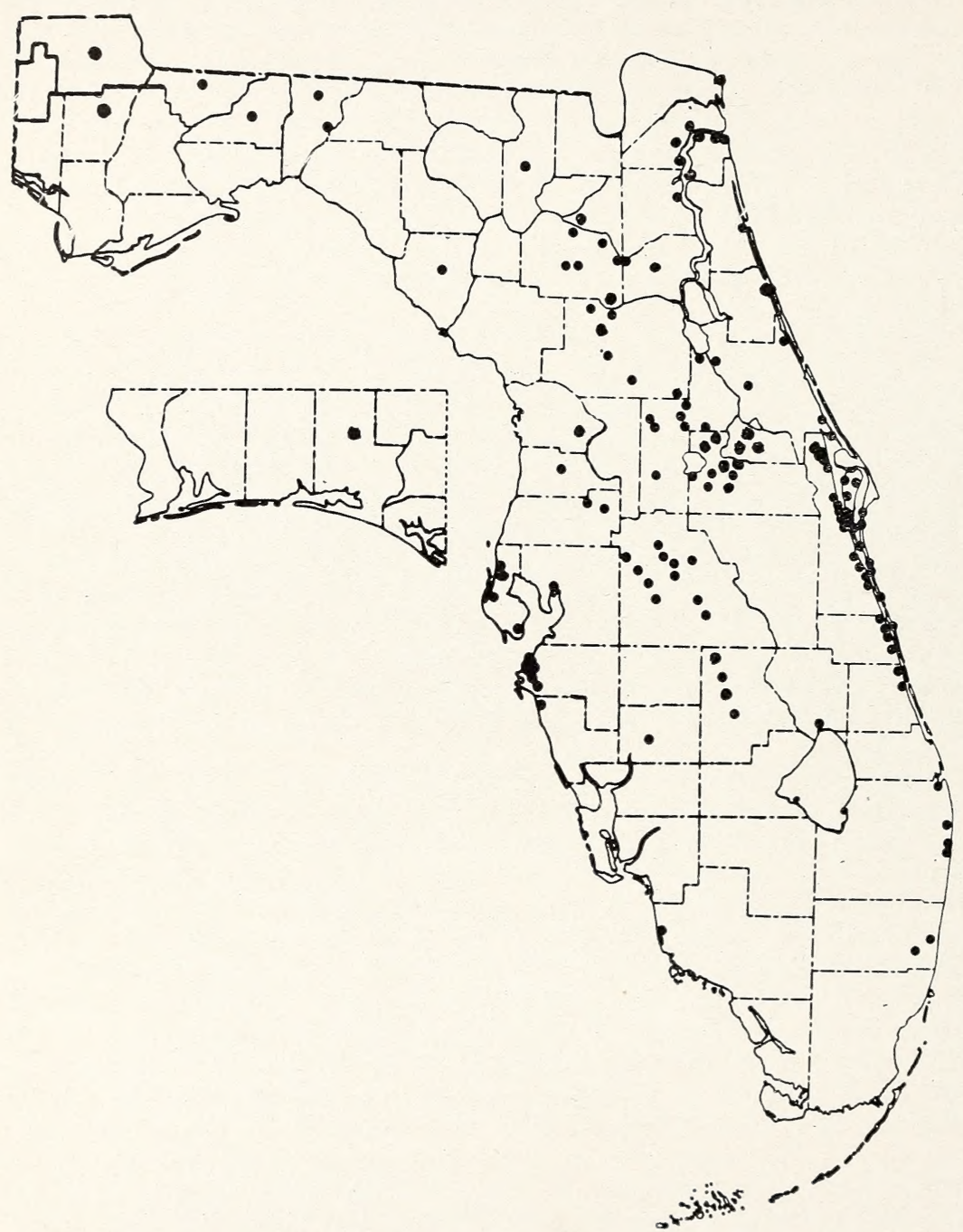

Figure 1.-Recorded distribution of Clitocybe root rot in Florida, the dots indicating localities where from 1 to more than 50 collections have been made.

and 59 families. Of these, members of the Casuarinaceae, Rosaceae, Leguminosae, Rutaceae, and Myrtaceae are represented with outstanding frequency. Conifers are attacked as well as broadleaf trees, and even bananas (23) and palms. The known distribution of Clitocybe root rot in Florida is shown in figure 1. 
Plakidas reported a crown girdle of sand pear (15) and tung trees (16) in Louisiana, with which $C$. tabescens was later determined to be associated, along with Dothiorella (Botryosphaeria) and sometimes other fungi. Clitocybe root rot was reported subsequently by Hines (11), Bain (2), Large (13), and the writer (24) as causing losses of trees in tung tree orchards in one or more of the following States: Louisiana, Mississippi, and Florida.

In Opelika, Ala., in July 1941, the writer observed two dead Lombardy poplars (Populus nigra var. italica), a nearly dead silver maple (Acer saccharinum), and a dying pomegranate (Punica granatum), all attacked by Clitocybe root rot. On the grounds of the experiment station at Auburn, Ala., where a number of peach trees had died a short time before from a trouble thought to be waterlogging of the clay soil, a peach tree (Prunus persica) and a wilting American plum (Prunus americana) also were found dying from this root rot. $C$. tabescens was isolated from the roots of each of these trees. Underwood and Earle (31) in 1896 and Earle and Austin (6) in 1900 reported a heavy mortality of grapes on the Alabama station grounds from a root rot of undetermined cause characterized by a whitish mycelial growth under the bark. Earle and Austin (6) stated that, of the 651 vines alive or planted in 1894,483 , or 75 percent, were dead by 1900 .

The economic importance of Clitocybe root rot varies greatly, according to the prevalence of the fungus in local areas, the age and extent of the planting, its esthetic or commercial value, and the susceptibility of the host species to the disease. Losses on numerous properties examined in Florida have varied from an occasional tree or shrub to serious losses continuing over a period of several years; the loss of scattered trees or groups of trees in commercial plantings of citrus, peach, and tung; or the loss of a majority of the trees in windbreak or roadside plantings of the highly susceptible Australian pine $^{3}$ or beefwood (Casuarina spp.). The occasional loss of a plant in a yard rarely causes much concern unless it is a particularly prized specimen. However, on properties where dying of plants continues over a period of years, losses may be extensive. When such losses occur on a large number of properties in Florida alone, it is evident that the aggregate losses in ornamental plantings become of considerable importance. Occasional properties in various parts of Florida have been found to be veritable hotbeds of infection for the Clitocybe fungus, with trees and shrubs thereon dying at frequent intervals over a period of several years. Properties at points in Florida where this fungus has been unusually destructive invariably have been hammock, pine-oak, or scrub oak types of land on which various species of oaks grew abundantly prior to clearing.

The writer has reported Clitocybe root rot in Florida on bananas (23), citrus (2\%), Australian pines (28), tung tree (24), and miscellaneous forest trees, fruit trees and ornamental trees, shrubs, and vines (23). At a Florida nursery a $3 / 4$-acre planting of closely set stock plants of both the India-rubber fig (Ficus elastica) and the variety variegata was being grown under a lath shed for commercial propaga-

${ }^{3}$ Although these trees are often called beefwood, the name Australian pine, by which they are generally known in Florida will be used in this circular. They are hardwoods, however, not pines. 
tion. Clitocybe root rot appeared on some of these plants. So destructive was the disease and so rapid was its spread that culture of the plants was discontinued within 5 years after the first apperance of the disease (26). In this case the unusually rapid spread and destructiveness of root rot was attributed to maintaining a high moisture content of the soil by daily use of an overhead sprinkling system to keep the moss layers wet.

\section{SYMPTOMS}

The symptoms of Clitocybe root rot vary considerably with the kind and size of the plants attacked and the rapidity with which girdling occurs. Root-rot symptoms are not apparent until the fungus has invaded the root system or root crown, or both, sufficiently to interfere with the life processes of the host plant. The dying of small trees or shrubs may follow rapidly, while that of large ones is likely to proceed much more slowly, with large trees often showing symptoms of decline for a few years before death.

On conifers, such as arborvitae and pines, a slight yellowing of the foliage may occur occasionally, but as a rule, at least on small trees, the foliage on the first limbs to be affected by the progress of the invading fungus simply turns brown and dies and the decline of the tree progresses more or less rapidly.

Small broadleaf trees and shrubs frequently are killed so rapidly that they may not develop any particular symptoms until they begin to wither and die. Large trees and shrubs usually show more or less yellowing and defoliation, accompanied by the rapid wilting and dying of individual limbs or trunk divisions. Finally, the whole plant dies. In other cases the wilting develops more or less simultaneously through the whole crown. When large trees or shrubs are not killed during the year in which they become partially girdled, the foliage developed the following year tends to show reduction in size, sparseness, and marked chlorosis, which usually increases in intensity toward the top.

In the case of Australian pine trees, the first symptom is a slight yellowing of the foliage branches, ${ }^{4}$ which generally develops first on the lower limbs of the crown on the side where the roots are first attacked. This yellowing soon becomes more conspicuous in extent and is accompanied by shedding of the affected foliage branches. As the disease progresses the crown acquires a thin, sickly appearance (fig. 2) and an unusually heavy litter of shed foliage branches accumulates under the tree. Attacked trees generally become about threefourths defoliated, and often completely so on the terminal parts of the crowns, before dying. However, in very young trees, where girdling proceeds quite rapidly, the foliage branches over the entire crown may turn brown and shrivel within a brief period without any preliminary yellowing and shedding. In older trees, where girdling may

\footnotetext{
${ }^{4}$ In these trees the leaves are reduced to whorls of mere scalelike teeth at intervals around the dehiscent foliage branches, which may appear to the layman as needlelike leaves.
} 


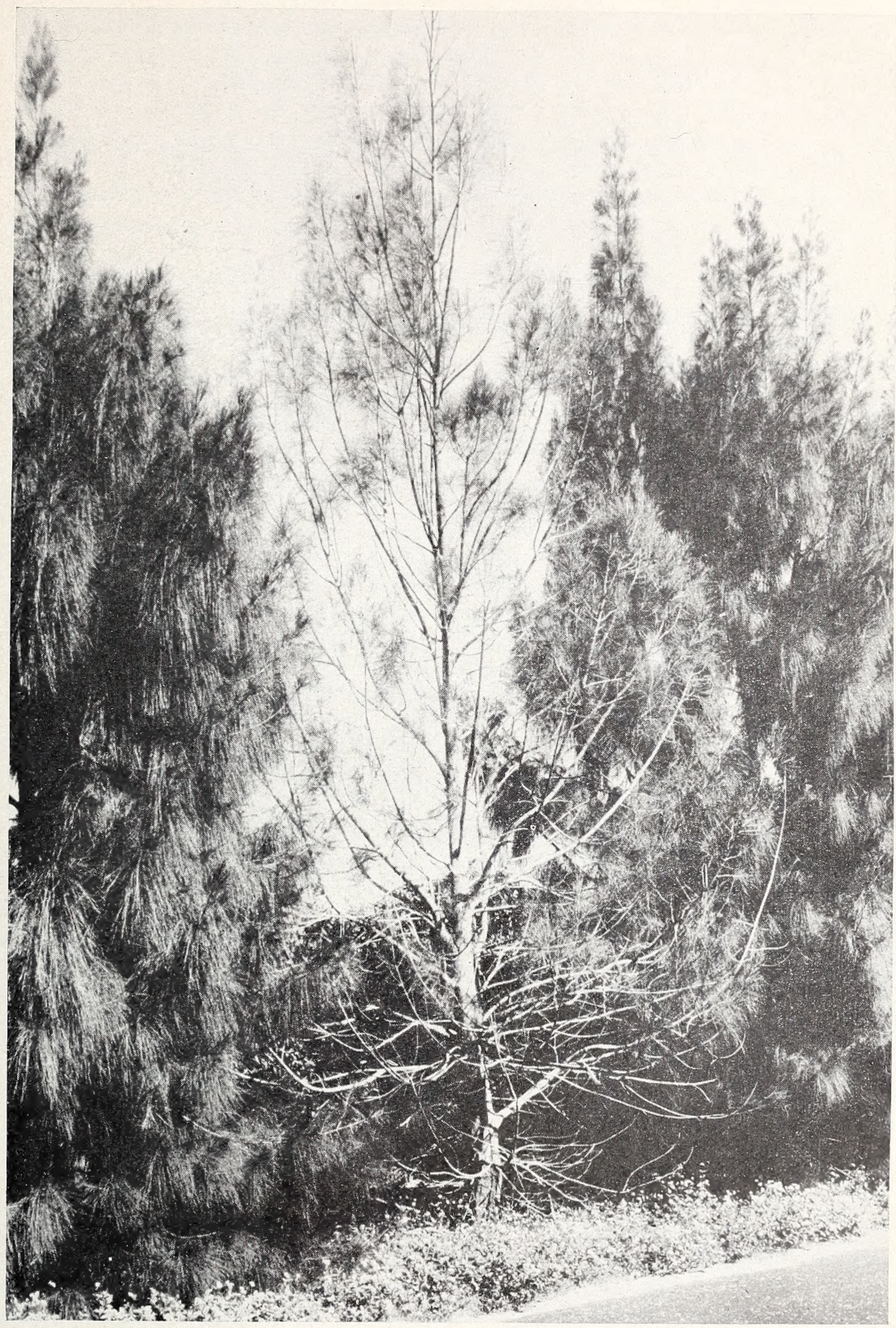

EIGURE 2.-Part of 10-year-old scalybark Australian pine windbreak, showing tree three-fourths defoliated from girdling by Clitocybe root rot, in contrast with healthy trees on either side. 
require 2 or 3 years from the time the first symptoms become apparent, new foliage branches may develop following the shedding of a large proportion, but the new ones usually attain only about half the normal length for the species.

By the time a pronounced yellowing or defoliation or other decline of the tops of attacked trees is apparent, the mycelial growth of the fungus usually has progressed upward on the base sufficiently so that its presence can be verified by making a cut in the bark down to the wood; though sometimes it may have developed only up one side of the tree. The upward progress of the mycelium at the base of the attacked tree frequently is indicated by a slightly sunken lesion. Such

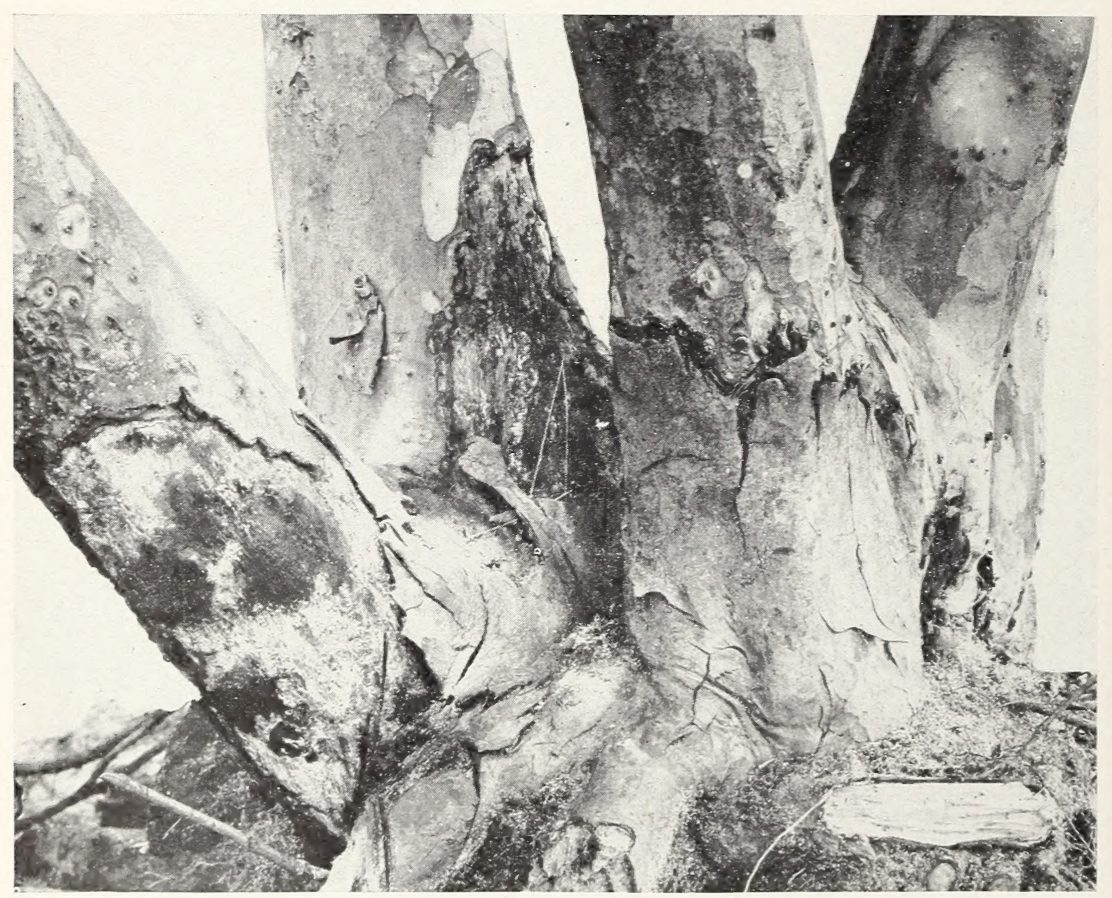

Figure 3.-Base of a large guava tree killed by Clitocybe root rot. Lesions extend up the trunk divisions; lead bark cracked loose on one at right, and shed on two at left.

basal lesions are most conspicuous on trees and shrubs with thin bark and do not show on thick-barked trees. They frequently develop first on one side before encircling the trunk. By the time the crown begins to become thin from defoliation, the cutting test of the bark usually shows the base of the tree immediately above the ground to be completely girdled. This girdling is often accompanied by longitudinal cracking of the bark as it dies, and sometimes also by a pronounced cracking, demarking the extent of the lesions (fig. 3). 'The basal lesions usually extend upward from a few inches to about a foot and rarely as high as 2 feet above the ground before the attacked tree dies, the height frequently being greater on one side than on the other. 
The mycelial sheets that develop under the bark are coextensive will the lesions (fig. 4).

In certain species of Australian pine trees the basal givlling by root rot frequently stimmlates a ponommed hypertrophy of the trumlis immediately above the girdled parts. Stome-firnit trees, streh as peach, plum, and ('arolina lamel(cherr, (ommonly develop more or less gum formation in the cambial region, which may be so copions as to exude through cracks in the bark.

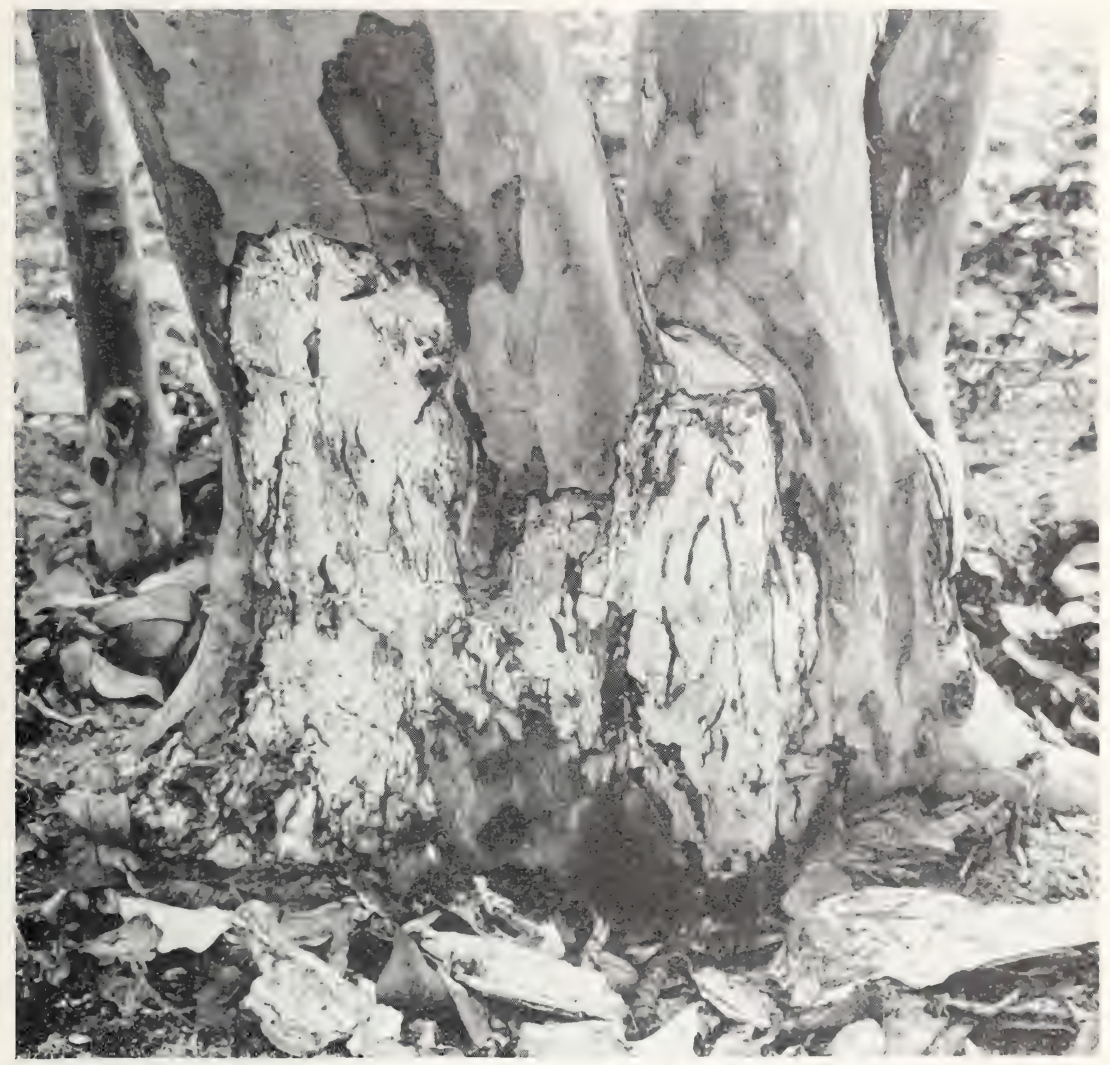

Figure 4.- Large guava tree dying from Clitocybe root rot. Dead bark has been cut away on basal lesion to show extent to which mycelium has spread up trunk.

When the batk of roots attarelied by ('litocybe root rot is peeled off. the myeeliun of the fungus is seen to have developed hetween the bat and the wood (fig. i) and also thromgh the inner layers of the batk. 'This varies from thin. lihm wefts to leathery sheets that are white when freshly developed but become ream- to rhamolis-olored with age. 'The mycelial sheets often show a more or less radiating, fanshaped type of development, but this feature is less conspicomont than usually occurs with Armillaria mollea and is less apparent in old, compact mycelial sheets. When especially favorable soil moisture corditions induce an unusually luxuriant givwth, the advancing mar- 


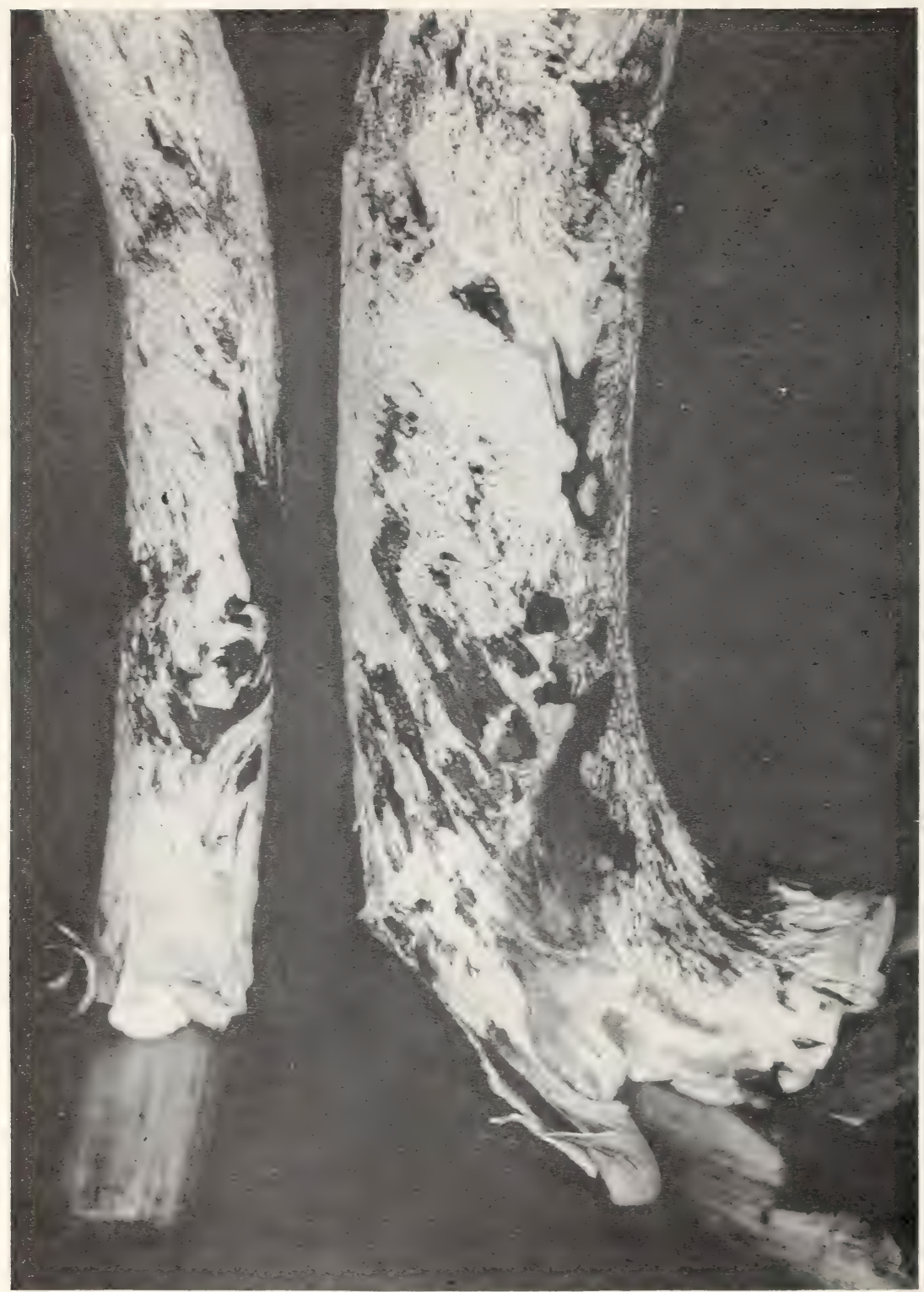

Fircti: J.- Roots of Bourbon Dombera bush dring from Clitocrbe root rot. Bark lias been peeled off to shom luxuriant growth of mycelial sheets dereloped during hot, ramy meather. Note thick, waxт malgin and perforate character of older parts.

gins of the mrcelial sheets may be considerably thickened (fig. 5). In addition to mycelial sheets of considerable extent, there may also derelop flattened, narrom to broad, thalluslike structures of the same color and either entire in outline or with numerous threadlike branching from the margins. These structures, which are essentially rhizo- 
morphic (rootlike) in character, are commonly produced in coltures of the fungus. In additional feature of the mycelial sheets is the frequent occurrence of a peculiar perforate character. clearly apparent (figs. o and 6). This appears to be a chatactel of cliagnost ic value for $C$. tabesens and one which apparently is not fomm in 1 . mellen. Freshly dug roots that show moredial sheets moler the bark are thatacterized by a proneunced mushroom or fungus odor.

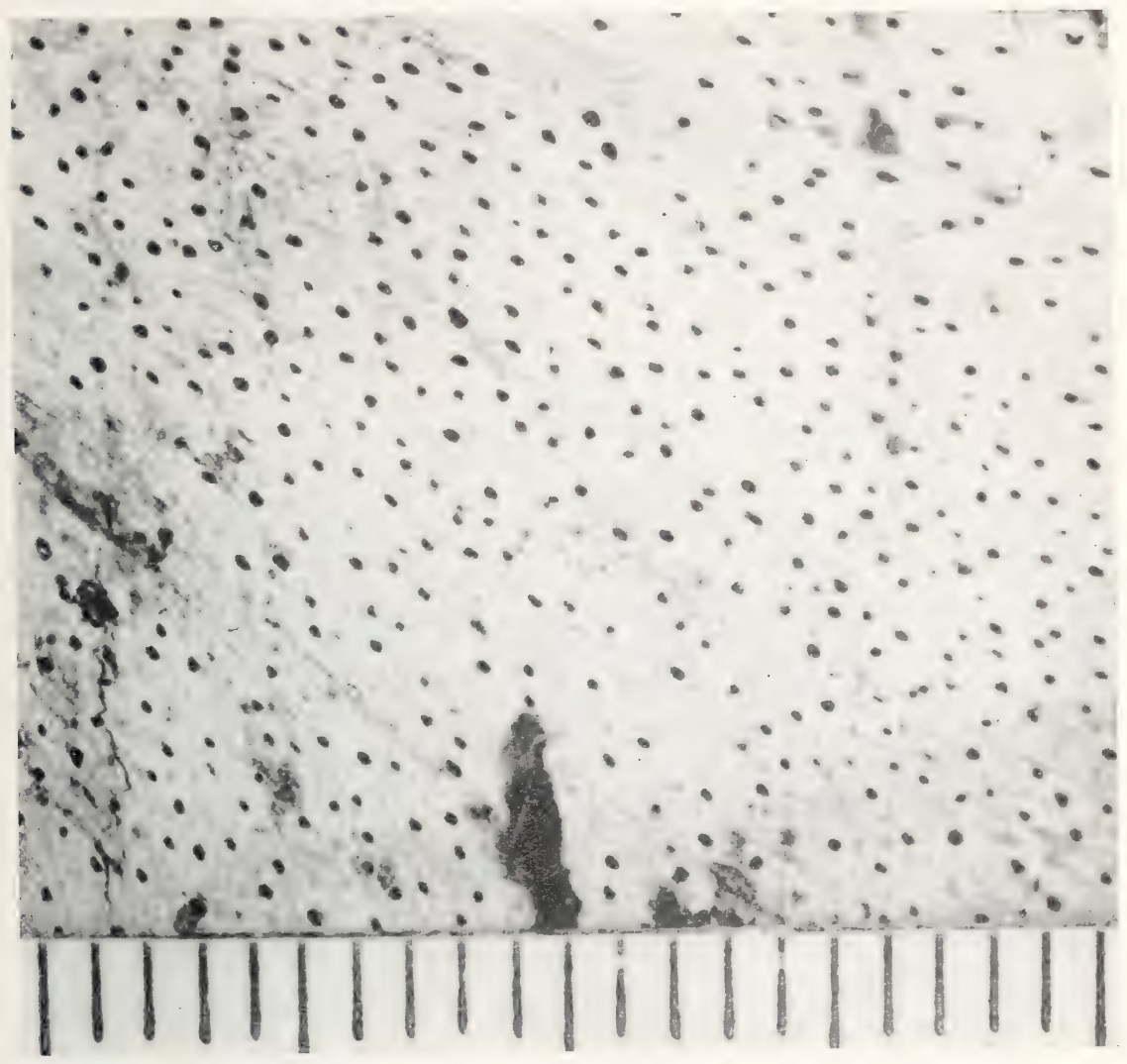

Figure 6.-Part of mycelial sheet developed between bark and wood of root of sand pine killed by Clitocybe root rot, showing perforate character and suggestion of radial growth. $\times 5$.

The black, rounded or flattened cortical or subterranean shoestringIike rhizomorphs so frequently accompanying the closely related root rot fungus A. mellea have not been observed to occur in the case of $C$. tabescens. However, a peculiar development of blackish. hardened. sometimes frilly, nycelial extrusions. similar to those reported for A. mellea, frequently occur on the bark of roots attacked by ( . tabescens. These structures originate as ontgrowths of the ingcelial sheets or xylostromata developed between the wood and the bark, becoming extruded through longitudinal fissures in the bark (fig. $T$ ).

An additional symptom of Clitocybe root rot is the ocamional development of clusters of the mushroom fruiting bodies of the fungus 


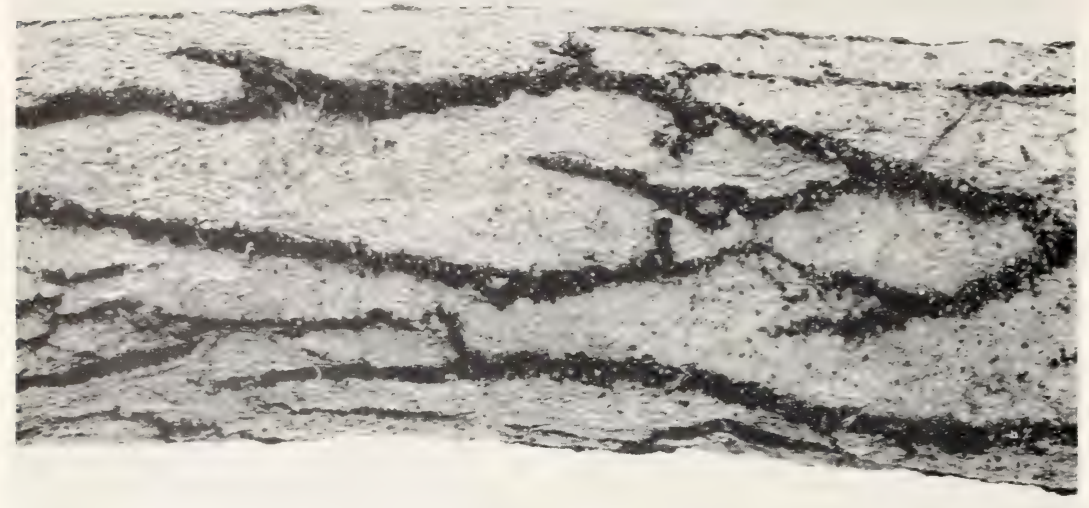

FIGTRE 7.-Root of seedling sweet orange tree attacked by Clitocybe root rot, showing blackish xylostroma extrusions developed through longitudinal fissures in the bark. Natural size.

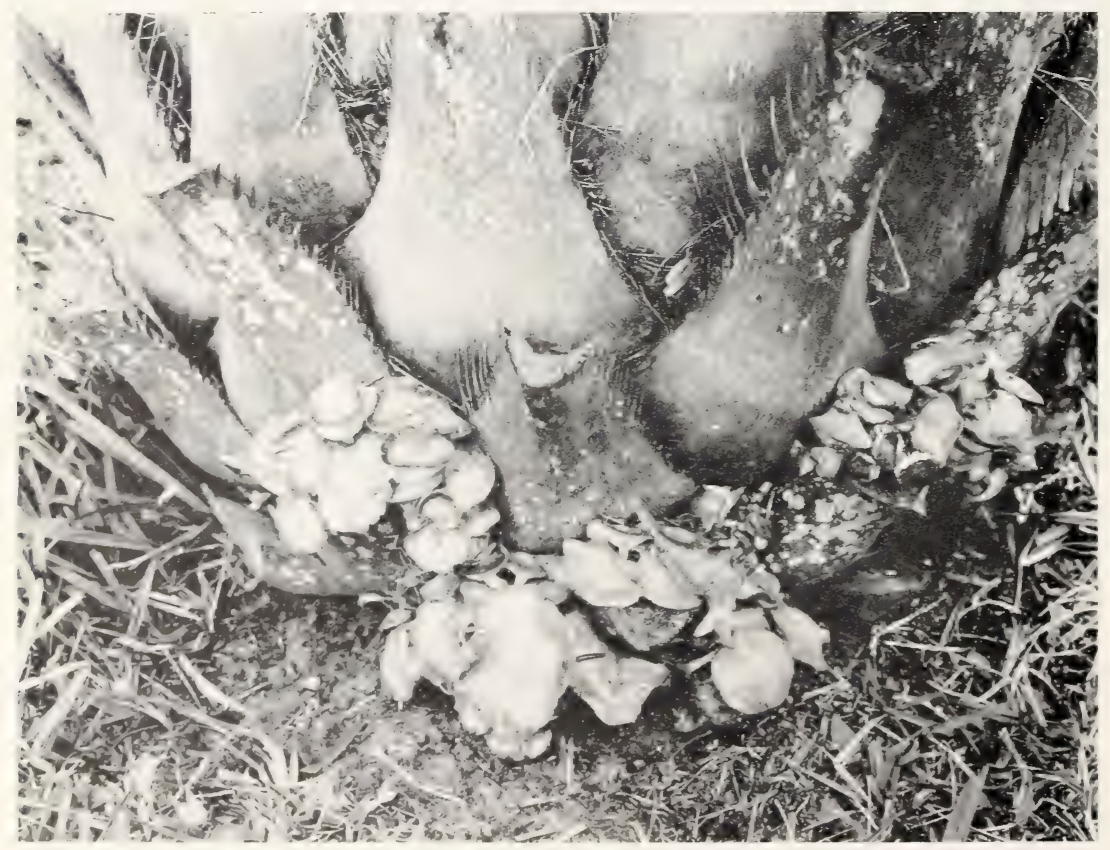

Figure 8.-Clitocybe tabescrns fruiting at base of Brazilian Butia palm attacked by root rot. Photo by Dr. George F. Weber.

at the bases of trees or shrubs that have been infected br it for some time (fig. S). The presence of one or more chusters of these growing from the roots or bases is an infallible sign that the root srstems have been more or less extensively invaded by the fungus, eren though symptoms of decline may not be apparent. 


\section{CAUSAL FUNGUS}

Clitocybe root rot is caused by Clitocybe tabescens (Fr.) Bres., one of the gill fungi. The fruiting bodies of this fungus consist of a few to many individuals, with the stems developing from a common base (fig. 9, A). When fully developed, the caps are convex to flattened or centrally depressed with age, whitish to light tan or honey-colored, smooth, or adorned with tufts of fibrils near the center, and from 2 to $3 \frac{1}{2}$ inches in diameter, with whitish gills underneath (fig. 9, $B$ ). The united Clitocybe, as this fungus is commonly called, resembles the closely related honey agaric (Armillaria mellea) in habit of growth, color, texture, and general appearance, but is distinguished principally by the absence of an annulus on the stem, dissimilar spores, and in being more slender from the beginning. It is considered superior to A. mellea in flavor and edibility. The latter fungus is of cosmopolitan occurrence and causes a very similar root rot.

The production of fruiting bodies by the Clitocybe root rot fungus depends largely upon the progress of the disease and the seasonal conditions. They develop with greatest frequency during the fall, though in Florida they occur most commonly from the middle of September to the middle of October, but may develop also in other months if favorable soil moisture conditions prevail. As a rule, only one or two clusters develop during the year and frequently none develop. They usually attain their full development within a few days from the time the young "buttons" appear and decay rapidly in warm, rainy weather. However, if dry weather follows their development, the clusters may dry up and turn dark brown to blackish but remain recognizable for several weeks to one familiar with the fungus. The presence of either fresh or old clusters of the fruiting bodies of the fungus frequently makes it possible to locate diseased trees, especially citrus, even before the tops begin to decline or the presence of the disease is suspected.

It should be borne in mind, however, that by no means every mushroomlike or toadstoollike fungus that may occur occasionally at the bases of trees is the particular species causing Clitocybe root rot. Aside from differences in character, other fungi are unlikely to be growing in clusters with several individual fruiting bodies arising from a common base at the foot of the tree and certainly will lack organic connection with the bark of the trunk or roots.

\section{ISOLATIONS OF THE FUNGUS}

Clitocybe tabescens has been isolated consistently from a diverse array of trees, shrubs, and vines attacked by mushroom root rot in various parts of Florida from 1924 to 1944. The only other organisms developing in these isolations were the ubiquitous bacteria, molds, and soil-inhabiting fungi that may be expected to occur as contaminations. In most cases a large percentage of pure cultures of $C$. tabescens resulted, while in others a large percentage of contaminations occurred. The root rot fungus develops very slowly, usually requiring from 1 to 2 weeks, and occasionally longer, for growth to begin. As a result, if any contaminations are present, they usually develop to the exclusion of the desired fungus. 

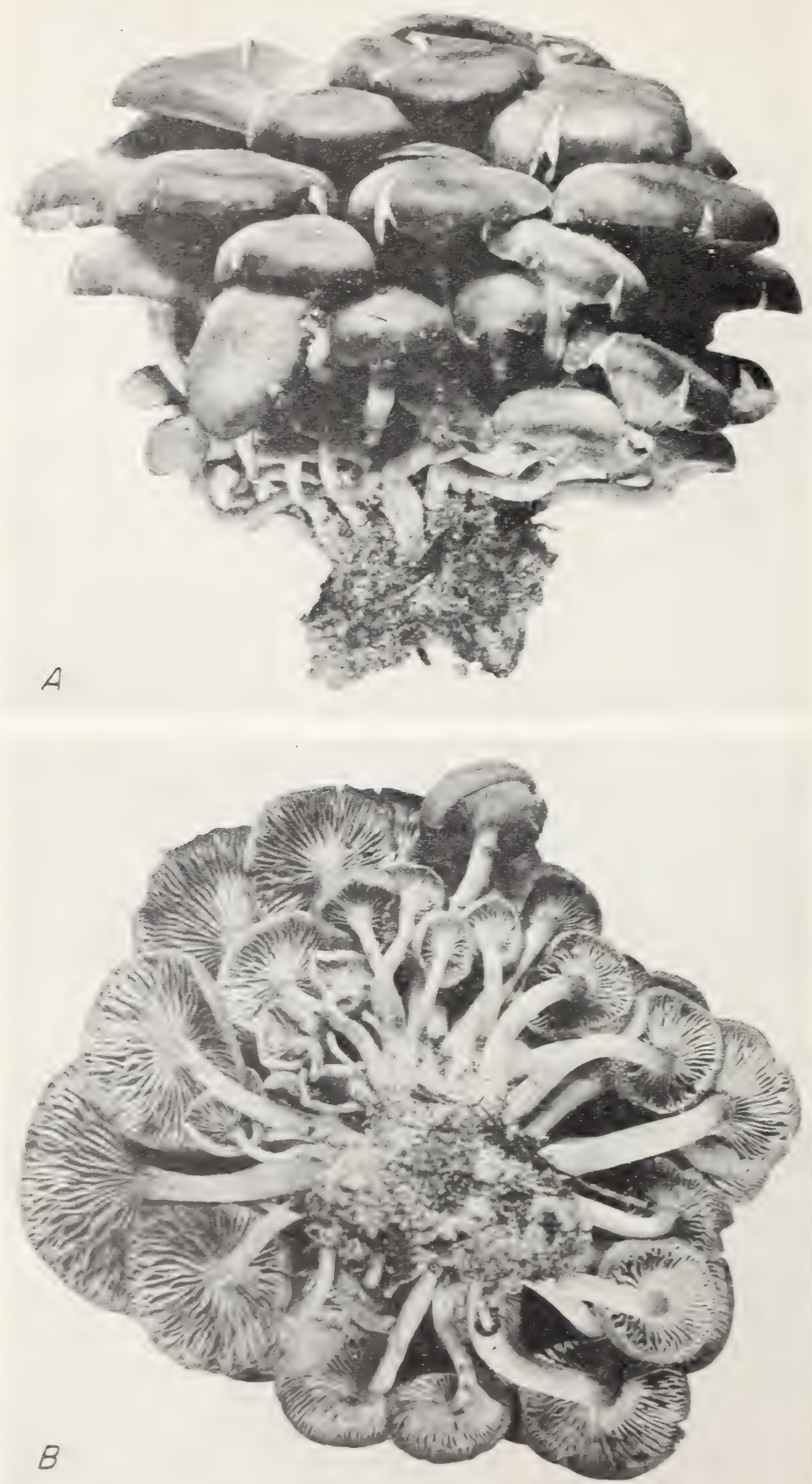

Figtre 9-A. Cluster of mushrooms of Clitocybe tabescens that dereloped on oak root left in cleared land, showing caespitose character. $B$, Under side of the cluster of mushrooms of $C$. tabescens shown in $A$, illustrating decurrent gills and lack of an annulus. 
After repeatedly isolating $C$. tabescens over a period of several years and carrying most of the isolates to the fruiting stage, there appeared to be no point in making further isolations, except in the case of inoculated trees or new host plants, though isolation of the fungus is always of value, especially when there is a possibility that the closely related root rot fungus Armillaria mellea may be involved. C. tabescens has been isolated from root material of 156 plants, comprising 90 species, from various parts of Florida. In the writer's extensive cultural work with mushroom root rot in Florida, only 2 instances, both at Gainesville, have occurred in which $A$. mellea was isolated and in both it was suspected when roots were collected that this fungus rather than $C$. tabescens was involved.

The writer has also isolated $C$. tabescens from infected grapevines in Missouri (19) and from five different kinds of trees in Alabama, as reported earlier in this circular. During the course of his work on Clitocybe root rot in Florida he compared isolates of this fungus from a number of sources outside of Florida with Florida isolates, and they were the same. Isolates from sand pear and tung-oil trees in Louisiana were received from Dr. A. G. Plakidas of the Louisiana Agricultural Experiment Station. Isolates from a Japanese cherry (Prunus sp.) at Washington, D. C., and from a sporophore that developed at the base of an eastern redcedar (Juniperus virginiana) at Arlington, Va., were received from $\mathrm{Mr}$. Ross W. Davidson, of the Division of Forest Pathology.

\section{INOCULATION EXPERIMENTS}

Various attempts to produce artificial infection with Clitocybe tabescens have been made by the writer over a number of years, beginning in 1931. The earlier attempts, which involved placing agar slants from large test-tube cultures against roots, both injured and uninjured, of native and exotic trees growing in woods and vacant lots, of potted woody plants in the greenhouse, and of Australian pine and citrus trees in buckets in a lath house were all unsuccessful. The ineffectiveness of this method was probably due to the short life of the inoculum in this unprotected state and to the relatively long time required for the fungus to infect the host.

It was not until after lengths of roots naturally infected by the Clitocybe root rot fungus were placed underground in contact with uninjured roots that infection took place, and even then several months elapsed before noticeable lesions developed. However, the writer's inoculation experiments were carried on under very droughty conditions. Successful artificial infections of horsetail and scalybark Australian pines (Casuarina equisetifolia and C. lepidophloia) finally were obtained, both through the use of pieces of naturally infected roots and pure cultures of the fungus grown on lengths of oak stems placed in contact with uninjured roots. In both cases the fungus was reisolated and carried to fruiting. Successful inoculation experiments with this fungus also have been reported by Plakidas (17), who was able to infect small Pineapple pear trees by placing blocks of wood, on which pure cultures of the fungus were grown, in contact with freshly wounded roots. 
Mechanical injury is not necessary for infection, since it has been observed repeatedly in field investigations that, like Amillaria mellea, $C$. tabescens can penetrate healthy roots readily through uninjured bark. The parasitic nature of this fungus is apparent from the readiness with which it attacks the most healthy and rigorous plants and the ease with which it may spread from one tree to another through root contact.

\section{RELATIVE SUSCEPTIBILITY AND RESISTANCE OF HOST PLANTS IN FLORIDA}

Little information is a vailable on the comparative susceptibility and resistance of various plants to Clitocybe root rot, even in Florida where the disease has been studied rather intensively. It is difficult to gather such data on the basis of the occasional dying of miscellaneous plants on various properties, since one rarely finds sufficient plants on individual properties to make reliable comparisons. Under these circumstances, comparisons of the susceptibility and resistance of plants can be made only by considering them with respect to the general prevalence of the disease in a large number of plantings in various parts of the State. It must be borne in mind, however, that the likelihood of susceptible plants being attacked raries greatly, according to the site on which they are planted. For example, eren the extremely susceptible Australian pines may prove fairly free from root rot when planted on low hammock, prairie, flatwoods, coastal beach, or other land that is free from infection, but very subject to it when planted on well-drained, sandy land where oak trees grew prior to clearing or some oak scrub remains.

The repeated occurrence of Clitocybe root rot on various species of Australian pine in widely scattered localities in Florida clearly demonstrates that these trees head the list of susceptible plants. These exotics are utilized extensively in Florida as windbreaks for citrus and other subtropical fruits, street and roadside trees, and screen, hedge, and other ornamental plantings. Aside from the susceptibility of some species to cold. their extreme susceptibility to this disease has proved the most serious drawback in many parts of the State to the extensive plantings of these very useful and extremely fastgrowing trees. The inroads of Clitocybe root rot frequently result in such widespread mortality of Australian pines that their usefulness or esthetic value is often rapidly impaired, or eren virtually destroyed, within a few years.

Peach trees also are extremely susceptible to Clitocybe root rot. This disease has proved to constitute an important factor of loss in a number of commercial plantings of tung trees. Citrus trees on rough lemon stock likewise hare proved quite susceptible to Clitocybe root rot, although it has not been found in those on sour orange stock. The common guara, sturdy crpress-pine, turkscap waxmallow, American arborvitae, eucalyptus, azaleas. and other plants have proved very susceptible. The disease also has been found to be the major cause of the dying of roses in Florida.

A general idea of the relative frequency of occurrence of Clitocybe root rot on the more commonly cultivated plants in Florida is giren in table 1 . The frequency with which it has been recorded on these 
TABLE 1.-List of plants in Florida on which Clitocybe root rot has been found 10 or more times

Common name

Horsetail Australian pine

India-rubber fig.

Scalybark Australian pine-

Peach

Tung tree

Rough lemon (rootstock)

Cunningham Australian pine

Common guava .

Sturdy cypress-pine

Coast Australian pine

Turkscap waxmallow

American arborvitae

Beakpod eucalyptus

Indica azalea

Chinese hibiscus

Swamp Australian pine

Brazil peppertree.

Sand pear

Camphor-tree

Turkey oak

Amur privet -

Australian pine

Loquat

Gaumachil apes-earring

Rose (rootstock unknown)

Oriental arborvitae

Silverleaf pumpwood

Laurel oak

Purple bauhinia

Grape

Common pomegranate

Carolina laurelcherry

Sand pine

Common poinsettia

Surinam-cherry

Cattley guava

Japanese rose (rootstock)

Oleander
Scientific name

Number of

diseased

plants

reported

14,500

22,500

660

1625

1375

330

149

102

1100

86

58

36

33

31

25

22

21

20

20

Cinnamomum camphora (L.)

Nees \& Eberm

Quercus laevis Walt

Ligustrum amurense Carr

Casuarina montana Leschen.

Eriobotrya japonica (Thunb.) Lindl.

Pithecellobium dulce (Roxb.) Benth.

Rosa $\mathrm{sp}_{\ldots} \ldots$

Thuja orientalis $\mathrm{L}$

Cecropia palmata Willd........ 14

Quercus laurifolia Michx._.

Bauhinia purpurea $\mathrm{L}_{\ldots} \ldots \ldots$

Vitis sp_................... 14

Punica granatum $\mathrm{L}$

Prunus caroliniana Mill_._._._.

Pinus clausa (Engelm.) Vasey _- 13

Euphorbia pulcherrima Willd - $\quad 12$

Eugenia uniflora $\mathrm{L}_{\ldots} \ldots \ldots \ldots$

Psidium cattleian um Sabine _...

Rosa multiflora Thunb_........ 10

Nerium oleander $\mathrm{L}_{\ldots} \ldots$

(4)

3

(1)

3

1

\footnotetext{
${ }^{1}$ In these cases losses of trees in some plantings occurred so extensively that the figures represent estimates rather than exact counts.

2 Number includes a single young ornamental tree and the estimated mortality on a $3 / 4$-acre planting of
} closely set stock plants grown under a lath shed.

plants, based on records extending over a period of 20 years, gives a general idea of the relative susceptibility of these plants to the disease. In Florida 210 species of plants have been recorded as hosts for Clitocybe tabescens. However, there are still many woody plants widely planted in Florida that have not been found infected as yet or appear to be attacked but rarely. Many plants that have been 
found to be attacked occasionally do not appear to be particularly susceptible. It has been noted that the occasionally infected oleanders and silk-oak Grevilleas sometimes fail to derelop the disease even though they occur in, or closely adjoining. plantings where Clitocybe root rot has killed Australian pine trees over a period of years. Moreorer, Chinese hibiscus appears to be much more resistant than turkscap waxmallow when they are planted together in situations where root rot is actire. Palm trees have rarely been found attacked and appear to be quite resistant. The writer observed a striking example of the way coconut and royal palms completely withstood the Clitocrbe root rot fungus in a mixed planting in which the majority of the horsetail Iustralian pines alternating with these palms died at an early age.

Clitocybe root rot has not been found thus far on allamandas or crotons, which occur commonly in many ornamental plantings where other plants have died from root rot. The mango has not been found attacked. though cccasionally growing in or near plantings where Australian pines have died, and only two instances of root rot have been observed on avocados. No instance has been found as ret on the widely planted cabbage palmetto. Citrus trees on sour orange rootstock have prored immune thus far, eren in groves in which Australian pines planted close to or among them have died extensively. Thile it is premature to state whether these or other trees will prove immune, the evidence arailable indicates that many plants clearly are much more resistant to the disease than others and that at least a few appear to be highly resistant, if not practically immune.

Thile a considerable number of trees native to Florida have been found attacked. most of these have been attacked but infrequently. The failure to find native forest trees attacked more frequently than has been recorded may be due in some measure to relatively little studr having been made of the occurrence of this disease in forested areas. Thile the oaks are favorite hosts for the saprophytic derelopment of the fungus, living trees do not appear particularly susceptible to infection. especially when roung. Although fairly mature oak trees in roods, partially cleared and developed areas, or yards of residential properties occasionally develop Clitocrbe root rot, it has been observed that the progress of this disease is often slow, with sereral vears being required to kill the trees. Judging by the resistance of caks and other native trees frequently found growing in situations where large numbers of Australian pine and other exotic trees have succumbed to root rot at an early age, the native roody plants of Florida appear rastly more resistant than many of those introduced from foreign countries or other States.

\section{RELATION OF INCIDENCE OF THE DISEASE TO TIMBERED) LANDS AND SOIL CONDITIONS}

Investigations on Clitocrbe root rot in a number of States, notably Oklahona, Missouri, Irkinsas, Louisiana. Mississippi, and Florida, have shown that the distribution of this disease comcides to a large extent with the location of areas where hardwoor timber, particularly oak trees, occur or were prevalent prior to clearing. As a general rule, it is absent on prairie and other lands where trees, particularly oaks, do not occur, and also on land where pure stands of pine timber occur. 
The disease has been found to develop on land formerly occupied by native hardwood forests, attracting no particular attention until from a few to several years after the land is cleared and planted to orchard or ornamental trees. The Clitocybe root rot fungus may remain riable for several years in infected roots left in the land at the time of clearing. These serve as sources of infection to trees subsequently planted. Thus trees, eren in orchards and other types of plantings, may contract the disease after several years in spots where the existence of the causal fungus was not even suspected. Occasional instances of Clitocybe root rot have been observed in residential properties where the land had been cleared for 20 or more years. In some cases trees have grown from 20 to 35 or 40 years before succumbing to root rot. The occurrence of the disease in such cases does not appear to be explainable on the basis of the roots coming into contact with old infected roots left in the soil at the time the land was cleared. It can only be inferred that infection may at times develop in some way other than by root transmission, presumably from spores.

The incidence of Clitocybe root rot in situations in Florida where hardwood timber occurs, or was prevalent prior to clearing, has been found to be by far the greatest on well-drained, light, sandy soils, which are dominantly acid in reaction and commonly subject to drought at frequent and often for prolonged periods. The disease also occurs in western Florida and Alabama on clay soils that are also acid. Losses from Clitocybe root rot occur infrequently on low hammock soils in Florida. Although these soils are characterized by the prevalence of oak and other hardwood trees prior to clearing, they are heavier and of greater moisture content than sandy soils, and usually neutral or alkaline in reaction, often being underlaid closely by marl or shell. On the other hand, the disease is unknown in Dade County, Fla., even in the extensive plantings of Australian pines and areas of natural reproduction of the horsetail Australian pine from Miami to Homestead. While oak trees occur here, the soils of this county are almost invariably alkaline, being closely underlaid by oölitic limestone. In view of this and of the fact that the disease sometimes occurs on land that has been cleared for many years and is free from old roots, it appears that some factor or factors other than the occurrence of infected roots in the ground to serve as sources of infection are involved in the incidence of the disease.

Clitocybe root rot also appears to be absent in the typical flatwoods sections of Florida, where the dominant regetation consists of pine trees and saw palmetto, and oak and other hardwood trees do not occur. It also appears to be absent in prairie lands. Coastal plantings of the extremely susceptible horsetail Australian pines in southern Florida on land made by dredging sand and shell from under salt water also appear to be characterized by complete freedom from root rot.

\section{CONTROL MEASURES AND TREATMENT OF DISEASED TREES}

Clitocybe root rot is one of those diseases against which it is much easier to take precautions in advance of planting than it is to apply remedial measures after the disease develops. Experience demonstrates that plantings of susceptible woody plant species on land where 
oak trees mere cleared a ferr years previously or on areas where oak scrub occurs in close proximity are very likely to be attacked at an early age. In fact. many such plantings of Australian pines in various parts of Florida hare proved extremely short-lived and losses have continued to occur over a period of several years.

In clearing land precaution should be taken to get out all the roots. Thile this is rarely possible. deep plowing prior to planting should prove very helpful. Any infected roots left in the land may serve as centers of infection to trees planted subsequently. Areas where oak trees were prevalent prior to clearing or where dead oak trees or stumps were left and interplanted often prove to be reritable hotbeds of infection for root rot in subsequent rears. Clusters of the mushrooms of the fungus frequently derelop around dead oak trees and stumps following rainy periods and disseminate mrriads of spores. Unless such sources of infection are remored completely, it is usually better not to plant trees that are particularly susceptible to Clitocrbe root rot.

Remedial measures to be employed after the disease derelops depends largely upon the nature. kind, and extent of planting, and the local circumstances. In an orchard or windbreak planting. the remoral of the first diseased tree or trees may prove helpful in curtailing further derelopment and spread, unless it starts from a number of sources. A timely cutting array of lesions of diseased bark at the bases of attacked trees and the remoral of the soil to expose the root cromm and adjacent roots to aeration and drying frequently will prove very effective in preventing the fungus from girdling the tree.

There diseased trees are remored, a soil fumigant such as carbon disulfide, which has been used successfully against Armillaria root rot in California orchards, should prove effective against Clitocybe root rot, although there is no record of it having been tried in Florida. Soil fumigation. horrerer, appears applicable only where diseased trees are to be removed.

In the early stages of Clitocrbe root rot on ornamental or other highly prized trees, careful surgical treatment may be effective. Unfortumately. howerer, the disease usually makes such extensive inroads before marked srmptoms of the diseased condition derelop that by the time the larman becomes a ware of the trouble and learns the cause it is cften too late to sare the trees. Investigation of the root cromn and root system often reveals that a large proportion of the root system is infected and the basal portion of the trunk more or less completely girdled, especially in young trees or shrubs.

Surgical treatment is tedious and painstaking and must be done by skilled workers. The extent to which the disease has attacked the root system can be determined only by remoral of the soil from around the root crom and adjacent lateral roots to permit a thorough examination. Remore the soil mithin a radius of at least 2 to 3 feet around the root crown, as shown in figure 10, working carefully to aroid injuring living roots. If facilities for forcibly washing the soil a way are not arailable. use a tromel. Remove the oil first from around the base of the tree and then around the lateral roots. Half of a post-hole rligger is an excellent implement for remoring the soil from around the root crown moler the lateral roots when they lie too close together to permit use of a shovel, 
If it is found practicable to treat the tree, cut off and completely remove all dead roots flush with the root crown or living roots from which they branch. Remove all dead oak or other foreign tree roots that may be found under the tree being treated. All bark lesions that may occur at the base of the trunk or on the root crown, lateral roots, or taproot, in case the taproot is not dead, shonld have the dead or infected bark cut out carefully back to healthy bark and down to somed wood. Carefully in-pect the lateral roots for local lesions, particularly at their juncture with the root crown. Remove all infected roots and chips of bark and wood cut away and burn them, since allowing such infected material to remain in the soil may lead to redevelop-

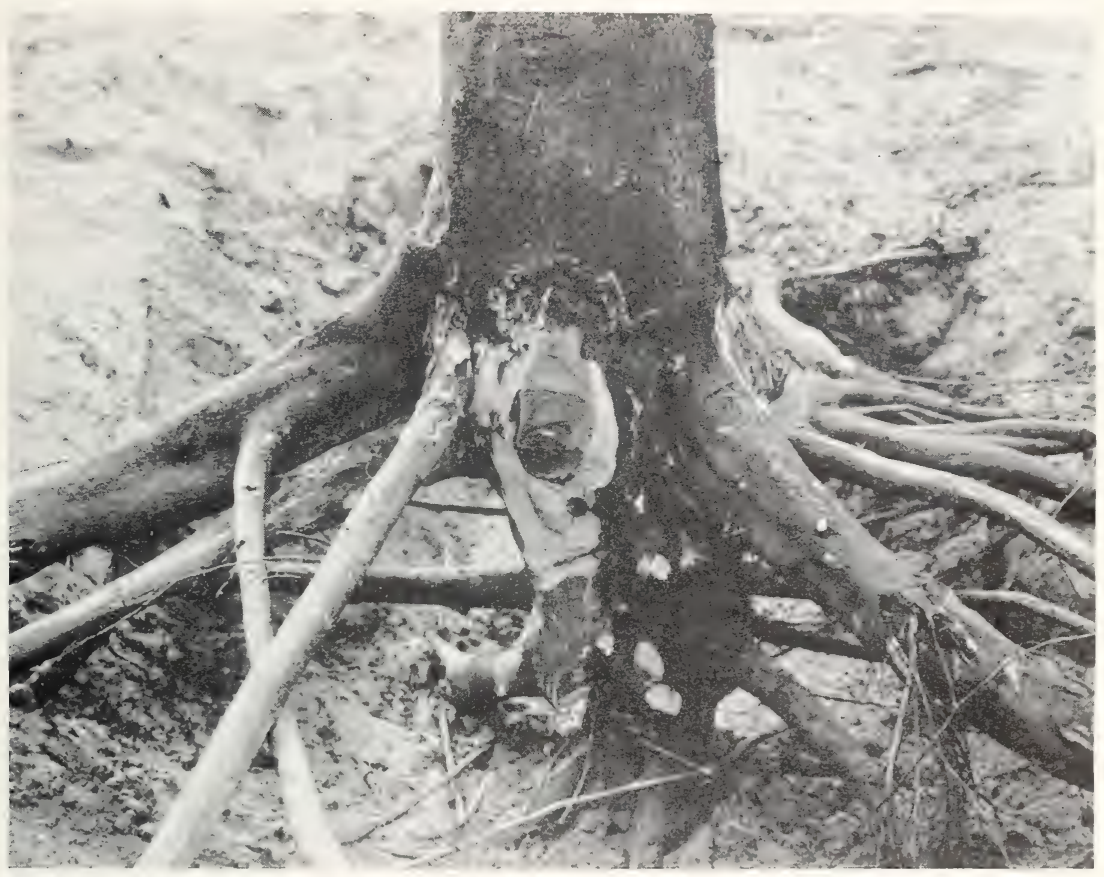

Figure 10.-Grapefruit tree on rough lemon stock given complete surgical treatment for Clitocybe root rot, showing points where the dead roots and diseased areas of bark were cut out.

ment of the disease. A piece of heary paper placed under the exposed roots will greatly facilitate the collection and removal of such material. All trees not worth treating should be removed, together with their roots. Figure 10 shows an example of dead roots and diseased areas of bark cut out on a treated tree, prior to painting.

After completing the surgical treatment the treated areas should be brushed clean of dirt and the roots inspected for any lesions that may have been overlooked. All exposed wood surfaces should then be painted with a good, durable pruning wound dressing. After this has dried the excavation may be filled in partially or completely. If the tree is not banked to stimulate the development of new roots, however, it is a good idea to leave the root crown exposed indefinitely for aer'a- 
tion and drying, except in sections where winter injury is likely to occur. A further disinfection of the roots, as well as the soil, while not necessary where a thorough surgical treatment is given, may be obtained by pouring 2 to 3 gallons of a strong bordeaux mixture $(5-5-50)$ into the soil basin. Extensive surgical treatment of trees sometines leads to decay of the exposed wood at bases of trees despite the use of a pruning wound compound.

The recovery of trees that have lost a considerable proportion of their root systems or have been partially girdled through root rot and its treatment often can be expedited materially by banking the soil around the bases to a height of several inches above the upper limit of the partial girdle to stimulate the derelopment of new roots from the

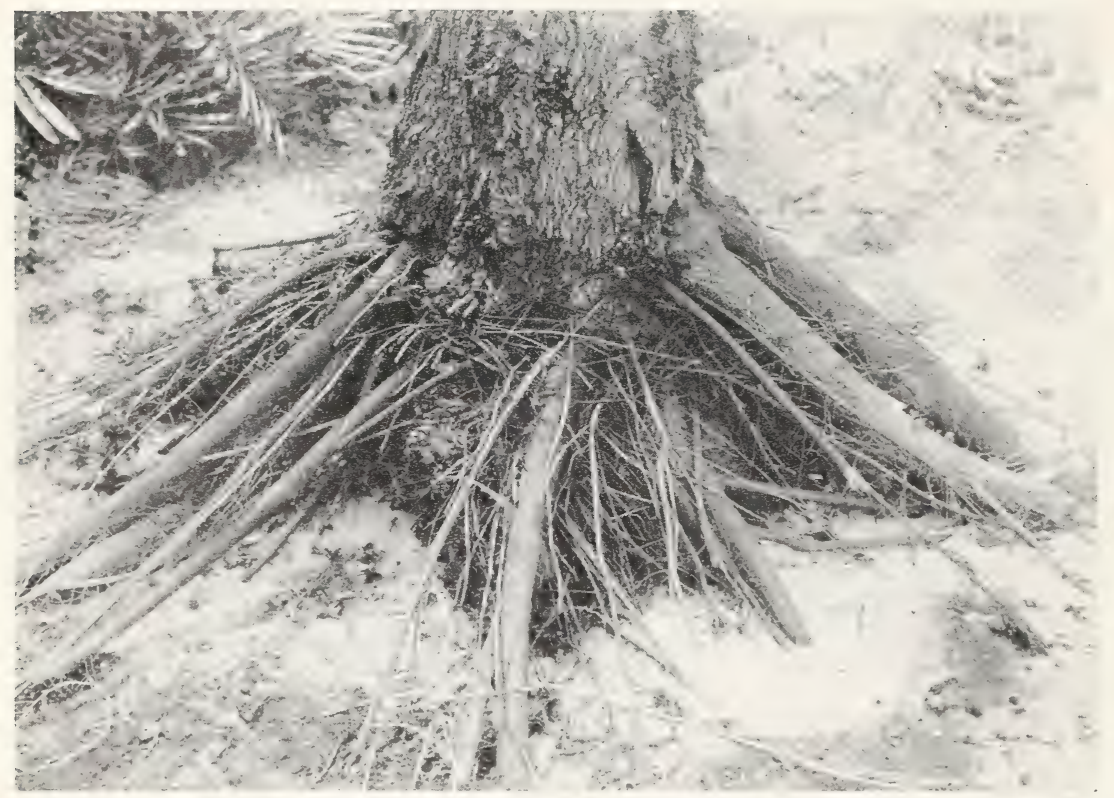

FigURE 11. -New root system developed on scalybark Australian pine by soilbanking method, following drastic surgical treatment for Clitocybe root rot in which all roots but three small lateral ones on one side of the completely girdled tree were removed. Photo made after washing away soil, less than $4 \frac{1}{2}$ years following treatment.

callus formed at the margin of the living bark. Under favorable moisture conditions new roots start developing within a few months, and within a year or two should attain sufficient derelopment to contribute materially to the recovery of the tree $(22)$. The efficacy of the soilbanking method of inducing the development of new root systems on trees is illustrated in figure 11.

\section{SUMMARY}

Clitocybe root rot, caused by the fungus Clitocybe tabescens, is re. ported as a destructive disease of woody plants in the southeastern United States. 
The root rot produced by this fungus is so similar in general aspects to that produced by the closely related root rot fungus Armillaria mellea, that in the absence of fruiting bodies or cultural studies, the diseases caused by these respective fungi may be confused readily. A. mellea occurs in all States where $C$. tabescens occurs, but in Florida $C$. tabescens is by far the more prevalent fungus.

Clitocybe root rot attacks not only native forest trees but also plantings of tung trees and a wide variety of fruit and ornamental trees, shrubs, and vines, including many exotic ones. In Florida, the only State in which this disease has been studied intensively, it has been recorded as attacking 210 species of plants belonging to 137 genera and 59 families.

$C$. tabescens has been isolated from roots of 156 plants, comprising 90 species, from various parts of Florida, and a number of isolations are reported from other States.

While this fungus commonly may live a saprophytic existence for years, it may also function as a virulent parasite and is capable of attacking uninjured roots of the most vigorously growing plants and spreading to adjacent ones, especially when closely planted. Its principal mode of transmission appears to be by root contact. Infected oak and other hardwood roots left in the land at the time of clearing have been found to constitute sources of infection to planted trees and shrubs for a much greater number of years than is generally believed.

The successful infection of Australian pines (Casuarina spp.), through both the use of pieces of naturally infected roots and pure cultures of this fungus grown on lengths of oak stems placed in contact with uninjured roots, is reported. In both cases the fungus was reisolated and carried to fruiting.

The incidence of Clitocybe root rot coincides to a large extent with the location of areas where hardwood timber, especially oak trees, occurred or was prevalent prior to clearing. In Florida, this disease has been found to occur most frequently in well-drained, light, sandy soils, which are dominantly acid in reaction and droughty in character, though it also occurs on clay soils in western Florida and Alabama, which likewise are acid. As a rule it occurs much less frequently on low hammock soils in Florida, which usually are neutral or alkaline, and is unknown on the alkaline limestone land of Dade County, even though oak and other hardwood trees occur in places. This and the fact that the disease sometimes occurs on land that has been cleared for many years and is free from old roots indicate that some factor or factors other than the presence of roots in the ground serving as sources of infection are involved in its incidence.

Preventive and remedial measures for the control of Clitocybe root rot are discussed. Surgical treatment and exposure of the root crown to aeration and drying have proved effective in combating the disease. Banking the soil to a point well above the partially girdled bases of treated trees, to stimulate the development of new root systems from the callus formed at the margin of the living bark, has been found to expedite materially the recovery of trees greatly weakened by loss of roots and partial girdling. 


\section{LITERATURE CITED}

(1) [Arkatsas Agricultural Experimext Statiox.]

1926. Plant Diseases. Ark. Agr. Expt. Sta. Bul, 203: 44-51, illus.

(2) BAIN, D. C.

1944. DISEASES IN TUNG TREE GROVES IN MISSISSIPPI AND LOUISIANA. U. S. Bur. Plant Indus., Soils, and Agr. Engin., Plant Dis, Rptr. 28: 1119-1120. [Processed.]

(3) Bresadola, G.

1900. FUNGI TRIDEXTIXI NOTI VEL NOXDUM DELINEATI DESCRIPTI ET ICONIBUS illestiati. V. 2, fase. 14, pp. 82-118, illus. Tridenti.

(4)

1928. ICoxographia Irycologica. จ. 3. 150 pp., illus. Mediolani.

(5) DUGGAR, B. M.

[1909.] FUNGUS DISEASES OF PLANTS, WITH CHAPTERS ON PHYSIOLOGY, CULTURE METHODS AND TECHNIQUE. 508 pp., illus. New York.

(6) Earie, F. S., and Acstin, C. F.

1900. grapes. Ala. Agr. Expt. Sta. Bul. 110: 53-91, illus.

(7) FAUROT, F. W.

1903. REPORT OF FUTGOUS IISEASES OCCCRRING ON CULTIVATED FRUITS DURING THE SEAsOx OF 1902. Mo. Fruit Sta. Bul, 6, 24 pp., illus.

(S) FATCETT. H. S.

1911. Report of Plant Pathologist. Fla. Agr. Expt. Sta. Ann. Rpt. 1911: $58-68$.

(9) Fromare, F. D.

1928. the black root rot disease of apple. Va. Agr. Expt. Sta. Tech. Bul. 34,52 pp., illus.

(10) Hewitt, J. L., and Haynurst, P.

1911. DISEASES OF APPLE TREES AND FRUIT CAUSED BY FUNGI AND INSECTS. Ark. Agr. Expt. Sta. Bul. 109: 411-145.

(11) Hrxes, L.

1940. the disease situation in turg. Amer. Tung Oil Assoc. Proc. 6 : 11-13. [Processed.]

(12) Hole. H. F.

1905. REPORT OF Mr. FRed H. Hole [ON PEAches.] Fla. State Hort. Soc.

(13) LARGE. J. R. Proc. 18: 88-91.

1945. TUNG DISEASES, 1945. Amer. Tung Oil Assoc. Proc. 11: 31-37. [Processed.]

(14) MIORgaN. A. P

1883. the MYCOLOgic fLora of the miami valtey. Cincinnati Soc. Nat, Hist. Jour. 6 : 64-81, 97-117, 173-199, illus.

(1.) Plakidas. A. G.

1936. CROT N GIRDLE OF PEAR TREeS. (Abstract.) Phytopathology 26: 105.

(16) 1937. Diseases of tUNg trees in Louisiana. La. Agr. Expt. Sta. Bul. 282. 11 pp., illus.

(17)

1941. infection with pURe cultures of clitocybe tabescens. Phytopathology 31: 93-95, illus.

(18) Preston, D. A.

1945. HOST IXdex OF OKLAHoya PLANT Diseases. Okla. Agr. Expt. Sta. Tech. Bul. T-21, $168 \mathrm{pp}$.

(19) RHOAds, A. S.

1925. ROOT ROT OF THE GRAPEVINE IN MISSOURI CAUSED BY CLITOCYBE TABESCENS (SCOP.) BRES. Jour. Agr. Res. $30: 341-364$.

(20) 1933. clitocybe mushroom root rot of woody plants. Fla. Agr. Expt. Sta. Press Bul. 454, 2 pp.

(21) 1940. CLITOCYBE MTSHROOM ROOT ROT OF CITRES AND OTHER ITOODY PLATTS IN florida. Fla. Agr. Expt. Sta. Ann. Rpt. 1940: 108-109.

1942. GROWIIG NEW ROOT SYSTEMS BY SOIL BANKIXG-A PROMISIXG METHOD OF REJUVEXATING TREES ATTACKED BY ROOT DISEASES. Phytopathology 32 : 529-536, illus. 
(23) RHOADS, A. S.

1942. NOTES ON CLITOCYBE ROOT ROT OF BANANAS AND OTHER PLANTS IN FLORIDA. Phytopathology 32: 487-496.

(24)

1943. diseases afFecting tUngoll plantations in florida. U. S. Bur. Plant Indus., Soils, and Agr. Engin., Plant Dis. Rptr. 27: 484-486. [Processed.]

(25)

1945. A COMPARATIVE STUDY OF TWO CLOSELY RELATED ROOT-ROT FUNGI, Clitocybe tabescens and armillaria mellea. Mycologia 37: 741-766, illus.

(26)

1947. AN UNUSUAL CASE OF CLITOCYBE ROOT ROT IN FICUS ELASTICA PROPAGATION STOCK IN A FLORIDA NURSERY. Phytopathology 37: 523-524.

(27)

1948. clitocybe root rot of citrus trees in florida. Phytopathology 38 : 44-61, illus.

(28)

[In press.]. THE DESTRUCTIVENESS OF CLITOCYBE ROOT ROT TO PLANTINGS OF CASUARINAS IN FLORIDA. Lloydia.

(29) Stevens, F. L., and Hall, J. H.

1911. NOTES ON PLANT DISEASES OCCURRING IN NORTH CARolina. N. C. Agr. Expt. Sta. Ann. Rpt. (1910) 33: 59-72.

(30) Thornton, R. P.

1940. peaches as a potential crop in south florida. Fla. State Hort. Soc. Proc. $53: 49-51$.

(31) Underwood, I. M., and Earle, F. S.

1896. treatment of some fungous diseases. Ala. Agr. Expt. Sta. Bul. 69 : $245-272$

(32) WALKeR, E.

1902. WHy APPLE TREeS FAIL. Ark. Agr. Expt. Sta. Bul. 71, 32 pp., illus.

(33) Wilcox, E. M.

1901. a rhizomorphic root rot of frutt trees. Okla. Agr. Expt. Sta. Bul. 49, 32 pp., illus. 




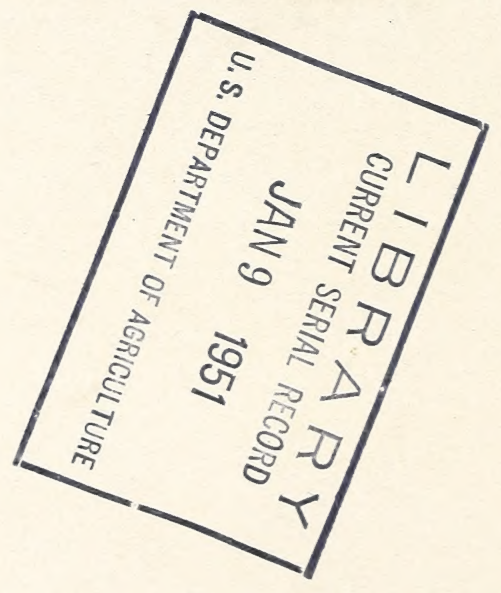



